\title{
18
}

\section{Public benefits, private benefits, and the choice of policy tool for land-use change}

\author{
David Pannell
}

\section{Key lessons}

- The selection of the best policy tool or delivery mechanism for an agri-environmental project depends crucially on the levels of public net benefits and private net benefits generated by the project.

- A framework is presented that recommends a policy mechanism from one of five categories: (a) positive incentives; (b) negative incentives; (c) extension (technology transfer, education, communication, demonstrations, support for community network); (d) technology development; and (e) no action.

- Private net benefits (which drive landholder behaviour) are just as important as public net benefits (e.g. for the environment) when selecting the policy mechanism.

- Australian programs tend to rely too much on extension and too little on positive incentives and technology development.

- Program managers can use the framework provided here to better match policy mechanisms to particular projects and programs. 


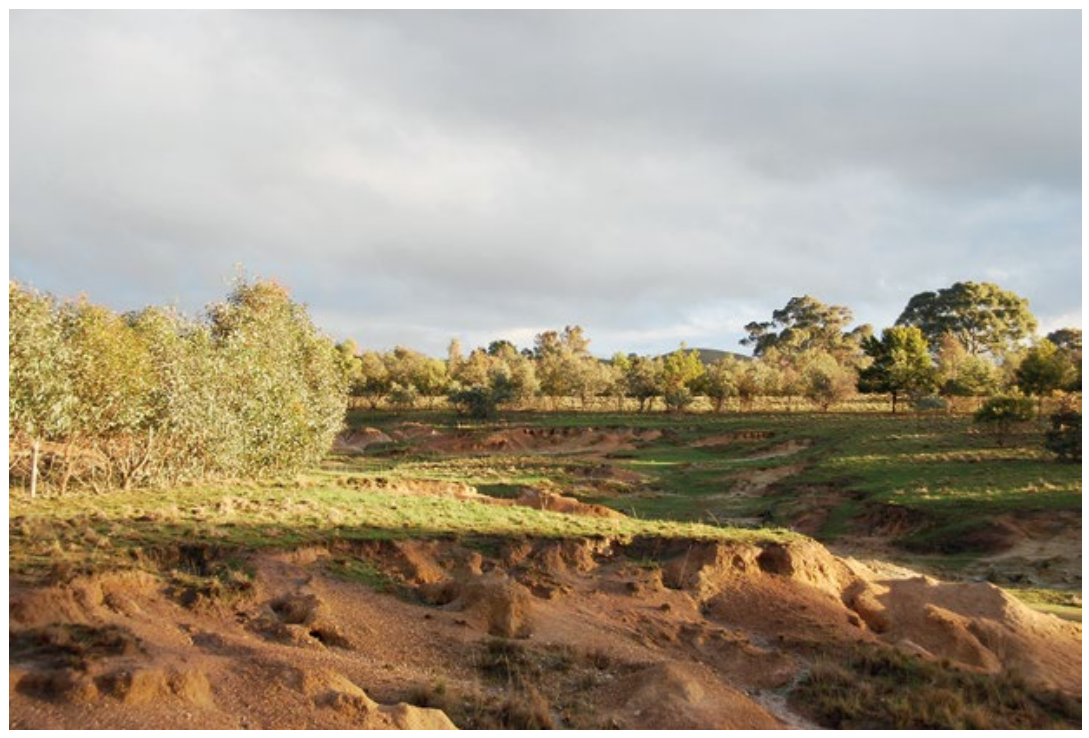

Figure 18.1: Conservation actions can generate private benefits - for example, addressing land degradation issues, such as erosion, that impact on agricultural production.

Source: Photo by Dean Ansell.

Agri-environmental programs around the world have been created to attempt to encourage changes in land management on privately owned lands in order to enhance environmental conservation or natural resource management (NRM). To encourage change, these programs use a range of policy mechanisms that can be categorised as (a) positive incentives (financial or regulatory instruments to encourage change), (b) negative incentives (financial or regulatory instruments to inhibit change), (c) extension (technology transfer, education, communication, demonstrations, support for community network), and (d) technology change (development of improved land management options, such as through strategic $R \& D$, participatory $R \& D$ with landholders, or provision of infrastructure to support a new management option). A fifth option available to governments is (e) no action, which can be appropriate if the cost of achieving a desired change is so large that it outweighs the resulting benefits, or if the benefits are expected to occur without government intervention. 
In practice, the choice among these possible policy mechanisms is often not very sophisticated. Programs primarily tend to rely on a small number of mechanisms, sometimes as few as one. The choice among these mechanisms depends on the levels of public net benefits and private net benefits from the land-use changes being proposed. Private net benefits refer to benefits minus costs accruing to the private land manager as a result of the proposed changes in land management. Private net benefits are the main driver of adoption of new innovations, and depend on a wide range of factors, not just profits (Pannell et al. 2006).

Public net benefits means benefits minus costs accruing to everyone other than the private land manager. Defining these terms in these ways is helpful because the private net benefit dimension provides insight into the behaviour of the landholder, while the public net benefit dimension relates to the effects on everyone else that flow from the landholder's behaviour.

\section{The Public: Private Benefits Framework}

In this chapter, I present the Public: Private Benefits Framework, a simple tool that helps to identify which type of policy instrument is most suitable for a particular agri-environmental project or program, based on the levels of public and private net benefits that are likely to result from the land-use change (Pannell 2008). It is useful in cases where environmental managers wish to influence the management of private lands to promote the conservation of natural resources or the environment. It is based on levels of public and private net benefits of changing land management, and a set of simple rules. It provides a powerful tool for targeting environmental investments to high-payoff projects, and for selecting policy mechanisms that are most likely to be cost effective.

The starting point for the framework is the recognition that agri-environmental managers can invest in a range of projects involving changes in land management or land use on private land, and that the available options vary widely in the levels of public and private net benefits they generate, potentially including negative net benefits. The aim is to identify which policy mechanisms are likely to be suitable for each potential project. 
To select policy mechanisms, the following set of rules is proposed, leading to Figure 18.2.

1. Do not use positive incentives for land-use change unless public net benefits of change are positive.

2. Do not use positive incentives if landholders would adopt land-use changes without those incentives.

3. Do not use positive incentives if private net costs outweigh public net benefits.

4. Do not use extension unless the change being advocated would generate positive private net benefits. In other words, the practice should be sufficiently attractive to landholders for it to be adoptable once the extension program ceases.

5. Do not use extension where a change would generate negative net public benefits. Note that rules four and five are referring to cases where extension is used as the main tool to achieve land-use change. Extension could also be used to support any of the other policy mechanisms, playing a supporting role rather than being the main tool.

6. If private net benefits are negative (but not overly negative), consider technology development to create improved (environmentally beneficial) land management options that can be made adoptable with or without positive incentives (Pannell 2009).

7. If private net benefits outweigh public net costs (such that the project would have negative net benefits overall — in other words, a net cost), the land-use changes could be accepted if they occur, implying no action, or they could be penalised at an appropriate level, but not prohibited. The latter approach uses a pricing mechanism to force landholders to consider the negative consequences of their actions. This allows them to weigh up whether their benefits exceed those negative consequences, thus making prohibition unnecessary.

8. If public net costs outweigh private net benefits, use negative incentives.

9. If public net benefits and private net benefits are both negative, no action is necessary. Adverse practices are unlikely to be adopted.

10. In all cases, the suggested action needs to be weighed up against a strategy of no action. 


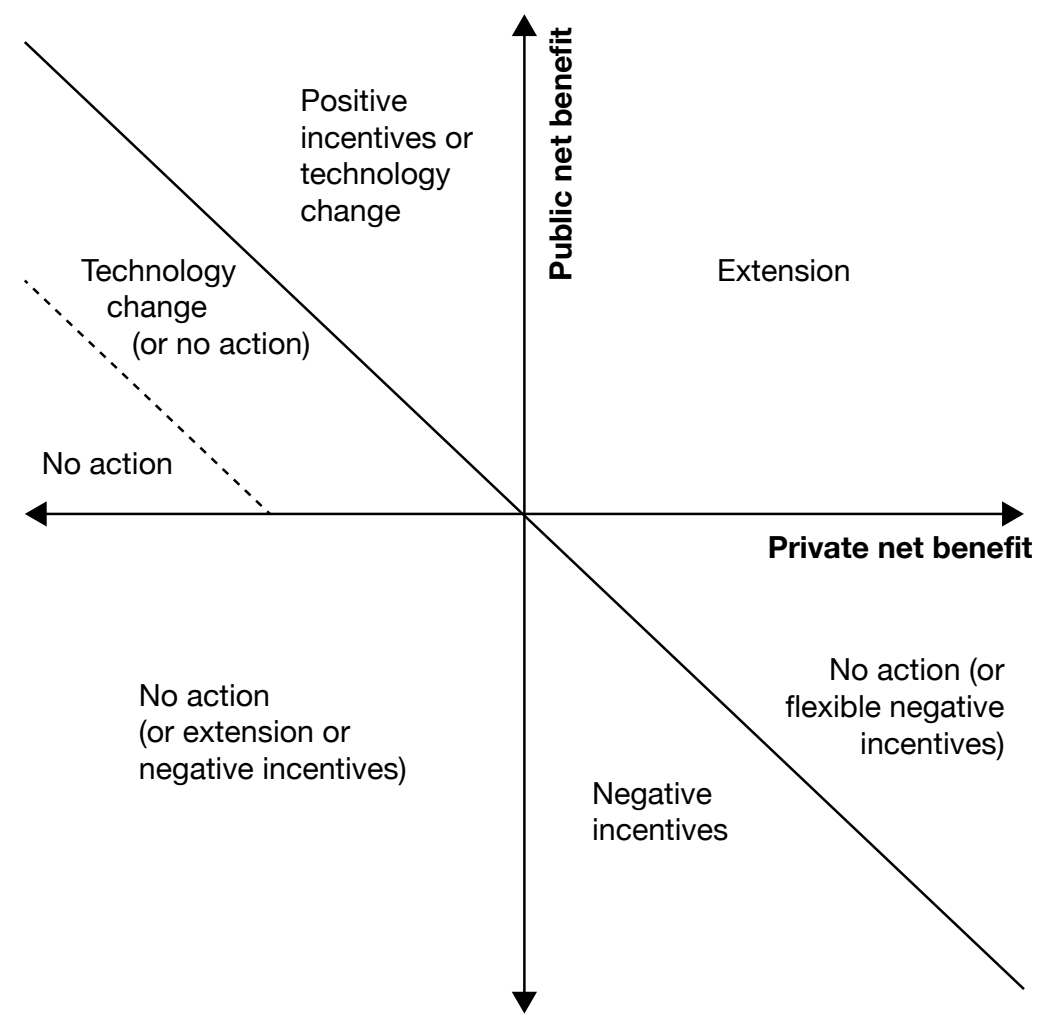

Figure 18.2: Recommended efficient policy mechanisms based on a simple set of rules.

Sources: Author's research.

For any given project, the levels of public net benefits and private net benefits, relative to current practice (which is represented by the zero-zero point in the centre), are estimated and plotted on the graph. Depending on the location of the project on the graph, the appropriate policy response is indicated. For advice on how to estimate public net benefits and private net benefits, see my 'Frequently Asked Questions' page for the framework: dpannell.fnas.uwa.edu.au/ppf-faq.htm.

Note that the zero-zero point remains the current practice no matter how good or bad that practice is with regard to public net benefits. The relevant questions addressed by the framework are (a) whether it is possible and worthwhile to do better than current practice, (b) whether it is worthwhile stopping or discouraging landholders from switching from their current practice to something more 
environmentally damaging, and (c) if so, how? These remain relevant questions whether the current practice is highly damaging or highly beneficial to the environment.

When estimating net benefits, if there are time lags until the realisation of costs or benefits, these should be discounted using standard discounting methods. The public and private net benefits that are graphed would thus be present values (Pannell and Schilizzi 2006).

This is quite a simple framework, but it is a good start. It significantly narrows down the range of policy tools that environmental managers should be considering depending on public and private net benefits in a particular situation. We can make it more sophisticated in various ways, including by allowing for time lags until adoption, learning costs involved in land-use change, the fact that extension reduces but does not eliminate lags to adoption, the transaction costs of extension, and through requiring higher levels of selectivity (a higher benefitcost ratio) than just covering costs. Figure 18.3 allows for these complexities, and requires a benefit-cost ratio of at least two.

In broad terms, the framework advocates the use of:

- positive incentives if the public net benefits of land-use change are high, and the private net benefits are not too negative;

- extension if the public net benefits of land-use change are high, and the private net benefits are moderate;

- no action if private net benefits are positive and public net benefits are not sufficiently high;

- no action if private net benefits are greater than public net costs;

- negative incentives if private net benefits are less than public net costs;

- no action if public net benefits and private net benefits are both negative; and

- technology development if private net benefits are low-tomoderately negative and public net benefits are positive (Pannell 2009). 


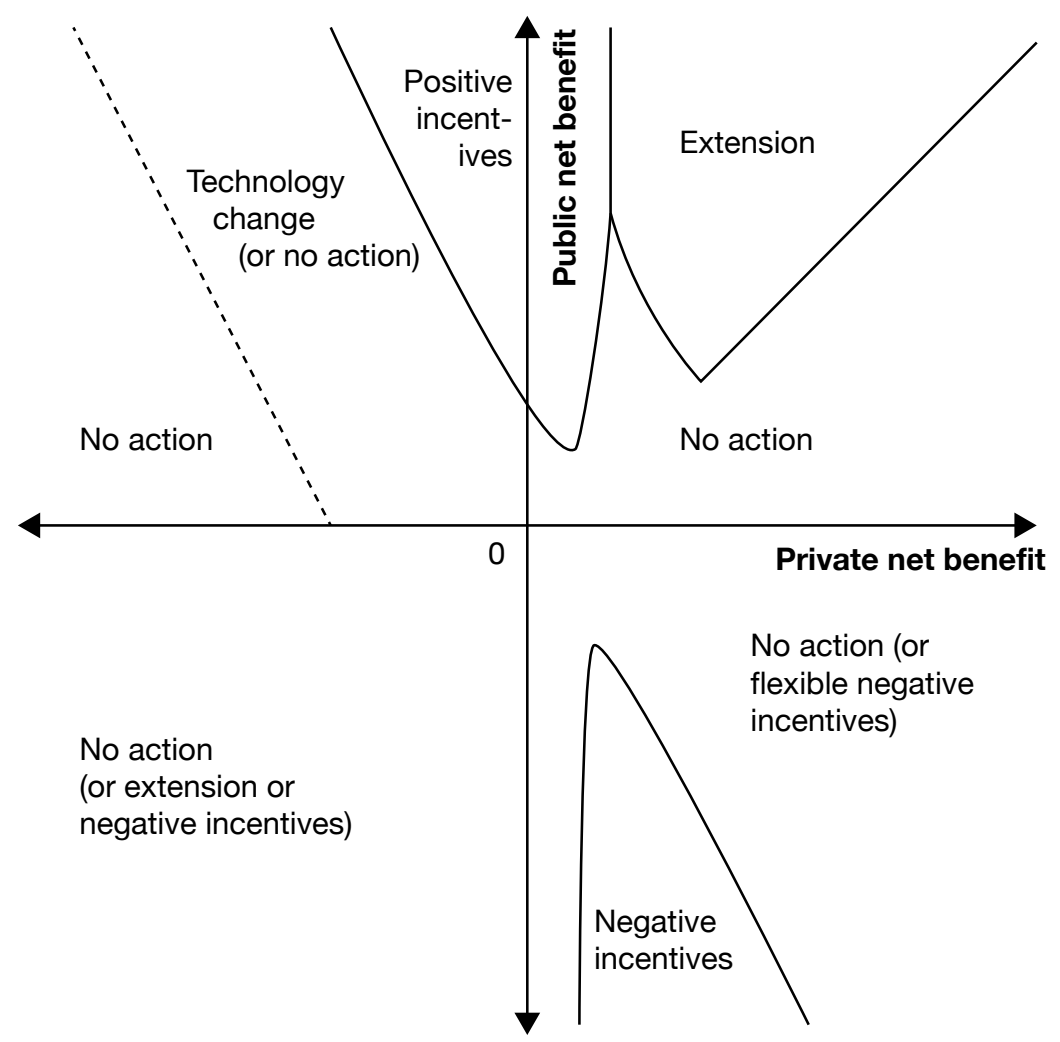

Figure 18.3: Efficient policy mechanisms for encouraging land use on private land, refined to account for various complexities described in the text. A smaller number of projects would qualify for incentives or extension in this more targeted approach, relative to Figure 18.2.

Source: Author's research.

Past Australian agri-environmental programs have often been inconsistent with these insights. For example, the National Action Plan for Salinity and Water Quality relied largely on extension and small temporary incentive payments (which are essentially a form of extension), but promoted practices that, in most cases, were not adoptable at the required scale (Pannell and Roberts 2010). For many of the land management strategies that were promoted, public net benefits were low (Graham et al. 2010) and private net benefits were highly negative (Kingwell et al. 2003), such that the projects would have fallen in to the 'no action' or 'technology change' sections of 
the framework's top left quadrant. The program made almost no investment in development of improved technologies for salinity management, even though this was the strategy most likely to succeed in many areas.

The Public: Private Benefits Framework is embedded within INFFER (the Investment Framework for Environmental Resources) (Pannell et al. 2012). When a project is evaluated using INFFER's Project Assessment Form, the location of that project on the Public: Private graph is provided as an output. The framework can be modified to suit particular contexts or target groups. For example, Pannell and Wilkinson (2009) adjusted it for lifestyle landholders (also known as hobby farmers). Their adjustments involved increasing the transaction costs per hectare (reflecting the small sizes of these properties) and increasing the private net benefits from environmental actions.

The framework highlights the importance of targeting funds in environmental programs to selected areas, based on the levels of public and private net benefits. Environmental managers tend to be focused on the level of public benefits when selecting their investments, but often pay inadequate attention to the level of private net benefits, which, perhaps surprisingly, turns out to be even more important as a driver of policy decisions.

It is worth noting that the rules underlying the framework are based on an objective of efficiency (biggest environmental benefit per dollar spent). In practice, governments often also pursue other objectives, ranging from perceived equity to raw political motives. I hope that by improving the understanding of what an efficient policy would look like, this framework can make it easier for that objective to be pursued.

\section{Acknowledgements}

Thanks to the ARC Centre of Excellence for Environmental Decisions and the Australian Government's National Environmental Research Program Environmental Decisions hub for funding support. 


\section{References}

Graham, T., D.J. Pannell and B. White (2010) 'Determining the netbenefits from government intervention for dryland salinity: A breakeven analysis', Australasian Journal of Environmental Management 17(2): 112-24.

Kingwell, R., S. Hajkowicz, I. Young, et al. (2003) Economic evaluation of salinity management options in cropping regions of Australia, Grains Research and Development Corporation, Canberra.

Pannell, D.J. (2008) 'Public benefits, private benefits, and policy intervention for land-use change for environmental benefits', Land Economics 84(2): 225-40. Available at: dpannell.fnas.uwa.edu.au/ ppf.htm.

Pannell, D.J. (2009) 'Technology change as a policy response to promote changes in land management for environmental benefits', Agricultural Economics 40(1): 95-102.

Pannell, D.J., G.R. Marshall, N. Barr, et al. (2006) 'Understanding and promoting adoption of conservation practices by rural landholders', Australian Journal of Experimental Agriculture 46(11): 1407-24.

Pannell, D.J. and A.M. Roberts (2010) 'The National Action Plan for Salinity and Water Quality: A retrospective assessment', Australian Journal of Agricultural and Resource Economics 54(4): 437-56.

Pannell, D.J., A.M. Roberts, G. Park, et al. (2012) 'Integrated assessment of public investment in land-use change to protect environmental assets in Australia', Land Use Policy 29(2): 377-87.

Pannell, D.J. and S. Schilizzi (eds) (2006) Economics and the future: Time and discounting in private and public decision making, Edward Elgar, Cheltenham, UK and Northampton, MA, USA.

Pannell, D.J. and R. Wilkinson (2009) 'Policy mechanism choice for environmental management by non-commercial "lifestyle" rural landholders', Ecological Economics 68: 2679-87. 
This text is taken from Learning from agri-environment schemes in Australia: Investing in biodiversity and other ecosystem services on farms, edited by Dean Ansell, Fiona Gibson and David Salt, published 2016 by ANU Press, The Australian National University, Canberra, Australia. 